\title{
Asaia lannaensis bloodstream infection in a child with cancer and bone marrow transplantation
}

Bacteraemia in cancer and transplant patients may be caused by opportunistic organisms including environmental contaminants (Krzywda \& Edmiston, 2002). We report what we believe to be the first case of bacteraemia caused by the environmental bacterium Asaia lannaensis and discuss its possible sources, including a central venous catheter (CVC), and review relevant literature.

\section{A 3-year-old Caucasian boy with} medulloblastoma in relapse, who had received an autologous haematopoietic stem cell transplant (AHSCT), underwent chemotherapy and craniospinal radiation followed by a second AHSCT. The patient received a preparative chemotherapy regimen of carboplatin, etoposide and melphalan followed by the AHSCT at a $\mathrm{CD} 34+$ dose of $3.73 \times 10^{6}$ cells kg ${ }^{-1}$. His post-transplant course was complicated by severe mucositis, pancytopenia and Clostridium difficile colitis diagnosed on day 6 post-transplantation (PT). He was successfully treated for the $C$. difficile colitis with metronidazole. On day 7 , he developed hypertonia and spastic posturing. Magnetic resonance imaging of the brain showed an old subdural haematoma and possible radiation necrosis in the brainstem. He underwent craniotomy and drainage of the haematoma, and was treated with intravenous meropenem and vancomycin because of the neutropenia and mucositis. He improved and engrafted by day 12 PT. His antibiotic treatment was changed to intravenous cefepime. On day 14 PT, he developed tachycardia, hypotension and fever up to $40.1{ }^{\circ} \mathrm{C}$. Blood cultures were obtained from both lumens of the CVC. Intravenous meropenem and vancomycin were restarted. Both blood cultures grew Gram-negative bacilli within $12-18 \mathrm{~h}$. The patient remained febrile and hypotensive and tobramycin was added to his treatment regimen. Because the CVC was a possible source of infection, the catheter was locked with $70 \%$ ethanol (the catheter volume plus $0.1 \mathrm{ml}$ ) according to our institutional protocol for sterilizing CVCs without removal. After $24 \mathrm{~h}$, the catheter was flushed with normal saline (Dannenberg et al., 2003; Onland et al., 2006).

Phenotypic methods misidentified or failed to identify the Gram-negative bacillus recovered from blood cultures. The organism exhibited high MICs for all antibiotics tested except gentamicin, tobramycin and tigecycline (Table 1). Meropenem was discontinued and the patient was treated with tobramycin for 14 days. Repeat blood cultures were negative. The patient showed progressive clinical improvement and was discharged from the hospital on day 36 PT. The organism was identified by 16s rRNA gene sequencing as A. lannaensis. The patient had no recurrence of infection during the subsequent several weeks.

The two sets of blood cultures obtained at the onset of fever on day 14 PT were incubated in an automated blood culture system (Bactec 9240; Becton Dickinson). After 12.5 and $27.2 \mathrm{~h}$ of incubation, the aerobic bottles grew a Gram-negative bacillus of variable length. The isolate was subcultured onto chocolate, blood and MacConkey aerobic agars and Columbia anaerobic blood agar. Small, pale rosecoloured colonies were detected on the blood and chocolate agars after overnight incubation at $35{ }^{\circ} \mathrm{C}$ in a $5-8 \% \mathrm{CO}_{2}$ atmosphere. The organism was motile, non-haemolytic, non-fermentative, oxidase-negative and catalase-positive. Tiny colonies appeared on the MacConkey plate, but only after $72 \mathrm{~h}$ of incubation.

Two commercial identification systems failed to identify the organism. The organism did not grow for identification and susceptibility testing in the MicroScan WalkAway 9600 (Siemens Healthcare Diagnostics). The organism grew in the API $20 \mathrm{NE}$ and $20 \mathrm{E}$ panels (bioMérieux) with the former unable to identify the organism and the latter identifying it as Acinetobacter baumannii. This was improbable because of the Gram-stain morphology, colony pigmentation, growth requirements and also the colistin resistance, which had not yet been seen in Acinetobacter baumannii in our hospital. Antibiotic susceptibility of the clinical isolate was determined using the Etest gradient agar diffusion methodology ( $\mathrm{AB}$ Biodisk).

Molecular identification of Asaia was performed by $16 \mathrm{~S}$ rRNA gene sequencing using the MicroSeq Bacterial Identification kit (PE Applied Biosystems) according to the manufacturer's instructions. The sequence was subjected to BLAST analysis at the NCBI website and showed $100 \%$ concordance with A. lannaensis (AB286051.1). To our knowledge, this is the first case of human disease caused by A. lannaensis.

Asaia is a recently described genus that contains three members, Asaia bogorensis, Asaia siamensis and Asaia krungthepensis, which were first isolated from flowers and fermented glutinous rice in Indonesia and Thailand (Katsura et al., 2001; Yamada et al., 2000; Yukphan et al., 2004). A. lannaensis was more recently isolated from the flowers of the spider lily collected in Thailand (Malimas et al., 2008). Three previously reported cases of invasive human infections with Asaia were all caused by A. bogorensis (Snyder et al., 2004; Tuuminen et al., 2006, 2007). The first was in a 41-year-old diabetic woman with end stage renal disease, on peritoneal dialysis, who developed refractory peritonitis and possible sepsis with a Gram-negative rod despite prolonged treatment with cefepime and ampicillin/sulbactam. She was treated with intravenous tobramycin and imipenem but required removal of the dialysis catheter (Snyder et al., 2004). The second case was in a 23-year-old man with a history of intravenous drug use who had Hill-Ewing sarcoma that required resection 
and knee prosthesis placement. His course was complicated by chronic enterococcal arthritis requiring prolonged treatment with amoxicillin/clavulanate and clindamycin. He then developed $A$. bogorensis bacteraemia, which was successfully treated with intravenous tobramycin and ceftriaxone based on susceptibility testing results (Tuuminen et al., 2006). The third case was in a 20-year old drug abuser who had fever and a blood culture positive for A. bogorensis (Tuuminen et al., 2007). Contamination of narcotic substances was postulated to be the source of bacteraemia in the latter two cases (Tuuminen et al., 2006, 2007).

Asaia species grow well at low $\mathrm{pH}(3.0)$ and at $30{ }^{\circ} \mathrm{C}$. They grow slowly at $34^{\circ} \mathrm{C}$, but are said to be unable to grow at $37^{\circ} \mathrm{C}$, which may explain the rarity of human infections caused by this bacterium (Katsura et al., 2001; Yamada et al., 2000). As in previous reports, the Asaia species from our patient was not identified by routine laboratory testing but by $16 \mathrm{~S}$ rRNA gene sequencing (Moore et al., 2002; Snyder et al., 2004; Tuuminen et al., 2006). This illustrates the importance of using molecular methods such as $16 \mathrm{~S}$ rRNA gene sequencing for correct identification of bacterial species when commercial methods fail.

Because Asaia species have not been recognized as human pathogens, there are no interpretative breakpoints for susceptibility testing. Consistent with previous reports, our isolate did not grow in Mueller-Hinton broth (Moore et al., 2002; Tuuminen et al., 2006), which is used by the MicroScan for susceptibility testing by microbroth dilution. However, it grew on chocolate and blood agars, which allowed susceptibility determination by Etest. Like previous $A$. bogorensis isolates, the A. lannaensis from our patient showed high MIC levels for almost all antibiotics that are used to treat Gramnegative rods including penicillins, cephalosporins, aztreonam,

fluoroquinolones, carbapenems and amikacin, suggesting resistance to these antibiotics (Table 1). However, gentamicin and tobramycin MICs were within the range interpreted as susceptible for nonfermentative Gram-negative bacilli (CLSI, 2008). Our patient was treated with intravenous tobramycin.

The source of infection in our patient is unknown. Given his underlying condition, he had no flowers and plants in his room. Our patient had mucositis, C. difficile colitis and a tunnelled CVC, any of which could have contributed to his acquisition of the infection. The exit site of the CVC was slightly erythematous and indurated but was not painful and exhibited no discharge. The CVC was locked with ethanol, which has previously been found to be a safe and effective method for decontamination and retention of infected CVCs (Dannenberg et al., 2003; Onland et al., 2006). Because it was not removed,

Table 1. Antimicrobial susceptibilities of reported Asaia species

Values are the MICs in $\mu \mathrm{g} \mathrm{ml}^{-1}$.

\begin{tabular}{|c|c|c|c|c|c|}
\hline Antibiotic & $\begin{array}{l}\text { A. lannaensis } \\
\text { (present report) }\end{array}$ & $\begin{array}{c}\text { A. bogorensis } \\
\text { (Moore et al., 2002) }\end{array}$ & $\begin{array}{c}\text { A. bogorensis } \dagger \\
\text { (Snyder et al., 2004) }\end{array}$ & $\begin{array}{l}\text { A. bogorensis (Tuuminen } \\
\text { et al., 2006) }\end{array}$ & $\begin{array}{c}\text { A. bogorensis } \\
\text { (Tuuminen et al., 2007) }\end{array}$ \\
\hline Amikacin & 16 & 30 & $S$ & 24 & - \\
\hline Aztreonam & $>256$ & 30 & - & $>256$ & - \\
\hline Cefepime & $>256$ & - & - & $>32$ & - \\
\hline Cefotaxime & $>32$ & - & - & $>32$ & - \\
\hline Ceftriaxone & $>32$ & - & - & $12 \S$ & - \\
\hline Cefuroxime & $>256$ & - & - & 24 & - \\
\hline Ciprofloxacin & $>32$ & - & - & $>32$ & - \\
\hline Colistin & $>256$ & - & - & $>32$ & - \\
\hline Gentamicin & 0.25 & - & $S$ & 3 & 0.25 \\
\hline Imipenem & $>32$ & 10 & - & - & 6 \\
\hline Tigecycline & 1.5 & - & - & 3 & 1.0 \\
\hline Tobramycin & 0.5 & - & $S$ & 8 & 1.5 \\
\hline $\begin{array}{l}\text { Trimethoprim/ } \\
\text { sulfamethoxazole }\end{array}$ & $>32$ & - & - & $>32$ & - \\
\hline
\end{tabular}

${ }^{\star}$ Isolated from contaminated fruit beverage.

$\dagger$ According to National Committee for Clinical Laboratory Standards criteria for Pseudomonas aeruginosa (document M100-S14, 2004). No MICs reported.

¥Ampicillin/sulbactam.

§Repeat testing showed higher MIC (not reported). 
no catheter tip culture could be performed to demonstrate whether it was involved in the infection.

Nahed Abdel-Haq, ${ }^{1,2}$

Süreyya Savaşan, ${ }^{2,3}$ Melissa Davis, ${ }^{2,3}$ Basim I. Asmar, ${ }^{1,2}$ Theresa Painter ${ }^{4}$ and Hossein Salimnia ${ }^{4,5}$

${ }^{1}$ Division of Infectious Diseases, Children's Hospital of Michigan, Detroit, MI, USA

${ }^{2}$ Carman and Ann Adams Department of Pediatrics, Wayne State University, Detroit, MI, USA

${ }^{3}$ Division of Hematology-Oncology, Blood and Marrow Transplantation, Children's Hospital of Michigan, Barbara Ann Karmanos Cancer Institute, Detroit, MI, USA

${ }^{4}$ Detroit Medical Centre University Laboratories, Detroit, MI, USA

${ }^{5}$ Department of Pathology, Wayne State University, Detroit, MI, USA

Correspondence: Nahed Abdel-Haq (nabdel@dmc.org)
CLSI (2008). Performance Standards for Antimicrobial Susceptibility Testing. Eighteenth Informational Supplement, pp. 46-51. Wayne, PA: Clinical and Laboratory Standards Institute.

Dannenberg, C., Bierbach, U., Rothe, A., Beer, J. \& Korholz, D. (2003). Ethanol-lock technique in the treatment of bloodstream infections in pediatric oncology patients with broviac catheter. J Pediatr Hematol Oncol 25, 616-621.

Katsura, K., Kawasaki, H., Potacharoen, W., Saono, S., Seki, T., Yamada, Y., Uchimura, T. \& Komagata, K. (2001). Asaia siamensis sp. nov., an acetic acid bacterium in the $\alpha$-Proteobacteria. Int J Syst Evol Microbiol 51, 559-563.

Krzywda, E. A. \& Edmiston, C. E., Jr (2002). Central venous catheter infections. Clinical aspects of microbial etiology and pathogenesis. J Infus Nurs 25, 29-35.

Malimas, T., Yukphan, P., Takahashi, M., Kaneyasu, M., Potacharoen, W., Tanasupawat, S., Nakagawa, Y., Tanticharoen, M. \& Yamada, Y. (2008). Asaia lannaensis sp. nov., a new acetic acid bacterium in the Alphaproteobacteria. Biosci Biotechnol Biochem 72, 666-671.

Moore, J. E., McCalmont, M., Xu, J., Millar, B. C. \& Heaney, N. (2002). Asaia sp., an unusual spoilage organism of fruit-flavored bottled water. Appl Environ Microbiol 68, 4130-4131.
Onland, W., Shin, C. E., Fustar, S., Rushing, T. \& Wong, W. Y. (2006). Ethanol-lock technique for persistent bacteremia of long-term intravascular devices in pediatric patients. Arch Pediatr Adolesc Med 160, 1049-1053.

Snyder, R. W., Ruhe, J., Kobrin, S., Wasserstein, A., Doline, C., Nachamkin, I. \& Lipschutz, J. H. (2004). Asaia bogorensis peritonitis identified by $16 \mathrm{~S}$ ribosomal RNA sequence analysis in a patient receiving peritoneal dialysis. Am J Kidney Dis 44, e15-e17.

Tuuminen, T., Heinasmaki, T. \& Kerttula, T. (2006). First report of bacteremia by Asaia bogorensis, in a patient with a history of intravenous-drug abuse. J Clin Microbiol 44, 3048-3050.

Tuuminen, T., Roggenkamp, A. \& VuopioVarkila, J. (2007). Comparison of two bacteremic Asaia bogorensis isolates from Europe. Eur J Clin Microbiol Infect Dis 26, 523-524.

Yamada, Y., Katsura, K., Kawasaki, H., Widyastuti, Y., Saono, S., Seki, T., Uchimura, T. \& Komagata, K. (2000). Asaia bogorensis gen. nov., sp. nov., an unusual acetic acid bacterium in the $\alpha$-Proteobacteria. Int J Syst Evol Microbiol 50, 823-829.

Yukphan, P., Potacharoen, W., Tanasupawat, S., Tanticharoen, M. \& Yamada, Y. (2004). Asaia krungthepensis sp. nov., an acetic acid bacterium in the $\alpha$-Proteobacteria. Int J Syst Evol Microbiol 54, 313-316. 